\title{
Innovation management and strategic planning of innovative self-preparedness and self-protection services
}

\section{Iris Gräßler}

Paderborn University - Heinz Nixdorf Institute, Product Creation Fürstenallee 11, 33102 Paderborn, Germany.

E-mail: iris.graessler@hni.upb.de

\section{Jens Pottebaum*}

Paderborn University - Heinz Nixdorf Institute, Product Creation Fürstenallee 11, 33102 Paderborn, Germany.

E-mail jens.pottebaum@hni.upb.de

\section{Philipp Scholle}

Paderborn University - Heinz Nixdorf Institute, Product Creation Fürstenallee 11, 33102 Paderborn, Germany.

E-mail philipp.scholle@hni.upb.de

\section{Henrik Thiele}

Paderborn University - Heinz Nixdorf Institute, Product Creation Fürstenallee 11, 33102 Paderborn, Germany.

E-mail henrik.thiele@hni.upb.de

* Corresponding author

\begin{abstract}
Due to climatic change, the number of high impact weather events is globally increasing. The European Commission aims at increasing the preparedness and protection of both citizens and enterprises to such events. The market potential of such services in public administrations is limited. Extending the scope to self-preparedness and self-protection is both promising and challenging. A novel approach for innovation management and strategic planning based on scenario-technique has been developed, applied and validated within four case studies of the European H2020 project ANYWHERE. The new approach combines fundamental domain knowledge, out-of-the-box thinking and agile scenario technique. Targeting both new innovative services as well as add-ons for established service frameworks was identified as key success factor of innovation in the difficult market of self-preparedness and self-protection services for citizens and enterprises.
\end{abstract}

Keywords: scenario-technique, self-protection, self-preparedness, disaster management, security market, high-impact weather events, weather forecast, impact assessment 


\section{Introduction}

Flash floods, thunderstorms and droughts are examples of extreme weather events caused by climatic change. Both the number as well as the impact of such events is globally increasing. The responsibility of preparedness and protection is shared among public authorities on the one side and citizens and enterprises on the other side. Therefore, The European Commission aims at increasing the level of preparedness through various initiatives. New innovative concepts and products usually target public protection and disaster relief organizations (PPDR). The market potential of such services in public administrations is limited. Extending the scope to self-preparedness and self-protection is both promising and challenging: The market for citizen or enterprise solutions is potentially larger, but lacks willingness to pay. Investments for risk reduction regarding personal health or business continuity are often neglected as long as risks are not tangible (Paton and Johnston, 2001), and governmental organizations are seen responsible for risk mitigation regarding natural hazards. The European H2020 project team of ANYWHERE developed a platform for impact assessment and decision support based on weather nowcasting and forecasting. Marking a paradigm shift regarding situational awareness from data analysis towards impact assessment, the platform offers broad potential also for innovative services for self-preparedness and self-protection.

A novel approach for innovation management and strategic planning based on scenariotechnique has been developed, applied and validated within four case studies: schools, food logistics, camp sites and electricity providers. The benefit of scenario-technique was proven in these four case studies. An additional case study with regards to generating product ideas for the automotive industries was performed with a German automotive supplier. Results from the project are summarized with the intention to share good practices of innovation management and strategic planning from the four case studies. On the one hand, potential dissemination of project results shall be fostered and potential innovators shall be addressed. On the other hand, a perspective on widening innovation potentials from a limited and regulated market to a broad variety of associated markets is outlined. The innovation fields of (self-)preparedness and (self-) protection in particular and of sustainable products in general are used as examples.

The paper at hand is structured as follows: Chapter 2 introduces challenges with regard to the specific domain of interest. Chapter 3 provides an insight into the European funded project ANYWHERE and specific ambitions targeting self-preparedness and selfprotection. Chapter 4 contributes the new approach enabled by Scenario-Technique. Chapter 5 presents related work to prepare for conclusions on strategic planning and innovation management in chapter 6.

\section{The market of services and tools for self-preparedness and self-protection}

The terms "self-preparedness" and "self-protection" indicate tasks and activities of individuals and organisations. They are performed with the goal to protect health (in case of individuals) and business (in case of organisations). In general, protection means to avoid any impact caused by actual hazards in a given situation. In contrast to that, preparedness means to anticipate potential hazards and to prepare countermeasures in advance. When it comes to large-scale and/or long-lasting disasters, the differentiation between preparedness and protection is fuzzy due to time and geographic dimensions. While for some regions 
protection might be necessary already, neighboured regions might still be in a state of raising preparedness levels. For instance, in case of droughts there might be regions with dry forests that have to protect themselves while others still prepare without activating protection measures yet. Nonetheless, the terms are significant regarding responsibilities (Venier and Capone, 2019): While PPDR organisations are in charge of protection, everyone needs to take actions in preparedness phase.

Services and tools to support self-preparedness and self-protection can be distinguished on a generic layer into a) those which are specifically dedicated to this domain and b) which are incorporate such functionalities into a broader field of application. The first category is clearly part of the so called "security market" (Gruchmann et al., 2014), while the second one is spread across various types of software systems. Dedicated services and tools for self-preparedness and self-protection can be sub-categorized into those provided or sponsored by public institutions, those that are driven by formal obligations and those that are driven by economic interests. For instance, the German Federal Office of Civil Protection and Disaster Assistance (BBK) offers a warning app called NINA to inform everyone about risks of natural hazards ${ }^{1}$. The app informs about official warnings as well as support regarding measures to self-prepare and self-protect. It is part of the services of BBK provided directly to citizens and enterprises. As an example for the second subcategory, critical infrastructures have to operate surveillance resp. monitoring systems to ensure immediate recognition of abnormal events. This obligation implies the generation of a specific market for software providers in the field of crisis management. The third subcategory results from economic considerations recognising safety as an economic value. Nonetheless, in these cases safety competes with various other values like comfort an easeof-use. Therefore, in these cases there is a tendency to integrate and offer functionality within broader platforms and services. Thus, markets of enterprise and private applications have to be distinguished. For enterprises, applications support business continuity and management of corresponding plans. This covers both compliance with obligations and reduction of economic loss. For instance, fleet management of trucks depends on accurate scheduling of travel durations. Thus, reducing the impact of extreme weather events helps to keep contracts and to satisfy customer demands. For citizens, applications support wellbeing and health. Examples spread from simple apps presenting travel advice including weather information to private cars that incorporate safety functions.

\section{The ANYWHERE project}

The ANYWHERE project was funded by the European Commission as an Innovation Action from 2016 until 2019. The goal was to design a platform that targets all aforementioned stakeholders: Within its main focus, the project created a platform to support decisions of PPDR organisations anticipating the impact of extreme weather events and coordinating countermeasures. At the same time, the project was driven by the intention to combine increased safety with the creation of market opportunities in the field of self-preparedness and self-protection.

${ }^{1}$ URL https://www.bbk.bund.de/DE/NINA/Warn-App_NINA_node.html (web page only available in German) 
This paper was presented at The ISPIM Innovation Conference - Innovating in Times of Crisis, 7-10 June 2020.

Event Proceedings: LUT Scientific and Expertise Publications: ISBN 978-952-335-466-1

The backbone of the ANYWHERE platform is built by weather models and according services. Input from hundreds of data providers as well as nowcasting and forecasting providers are integrated by the so called Multi-Hazard Early Warning System (MH-EWS) (van Lanen et al., 2019). Figure 1 presents MH-EWS as the "mainframe" of the entire platform. It provides various types of services to PPDR applications (called A4EU) as well as third party integrations for different domains. Eight pilot installations of A4EU were realised within the project, for instance, in Catalunya, Liguria and Corsica. The adaptation to local need and the integration of local data sources are key elements of ANYWHERE services within the ANYWHERE eco-system. PPDR applications already include functionality to prepare and send warnings to the public through legacy systems. In addition, MH-EWS services are applicable for self-preparedness applications. Citizens or enterprises can use impact assessments directly without waiting for public warnings. The interrelations were tested by role-playing games (Terti et al., 2019).

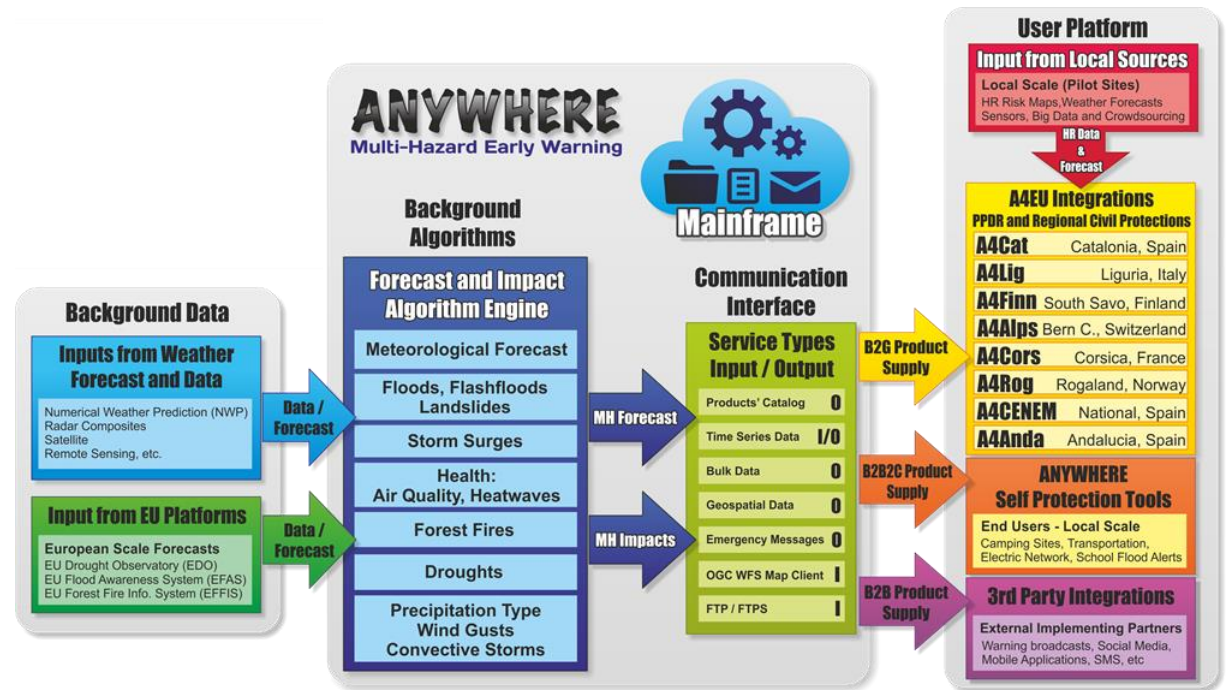

Figure 1 Overview of the ANYWHERE platform (Source: ANYWHERE consortium).

The paper at hand focuses on innovation in self-preparedness and self-protection: How to overcome the hurdles of this specific market based on MH-EWS services? Figure 2 shows the ANYWHERE approach: In continuous alignment with PPDR stakeholders and procedures, literature was analysed to identify requirements and constraints for dedicated self-preparedness tools as well as integrated functionality (cf. chapter 2). Guidelines and recommendations are used to open up a Common Information Space facilitating cooperation and alignment amongst stakeholders. Utilising this space as an information resource, creativity techniques were applied to open up a broad field of potential applications. Three are marked by red colour: for a Catalan association of campsite operators, a system was provided to operate response to the European Floods Directive; for a Finnish transmission grid operator, a system to schedule response capacities in case of thunderstorms was created; for Italian and Spanish flood logistics companies, fleet management was extended by an assessment of snow and flood impacts on traffic conditions. A fourth case is presented in chapter 4 focusing on automotive industries. An engineering supplier considers the adoption of MH-EWS services into a platform for autonomous driving. Both technical and market potentials have to be investigated. 


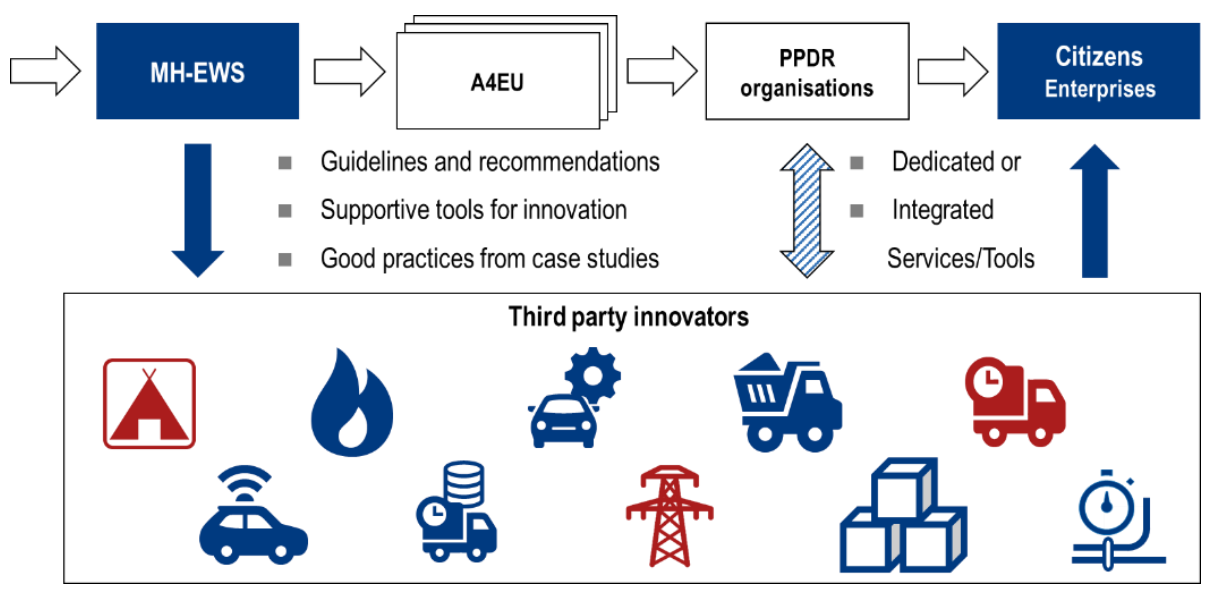

Figure 2 Stakeholders and services/tools in self-preparedness and self-protection.

\section{Amplified innovation by agile Scenario-Technique}

Within the ANYWHERE project, a novel approach for innovation management and strategic planning was developed. The approach is a consistency-based approach towards scenario-technique based on the procedural model for agile scenario-technique by Graessler and Scholle (Graessler et al., 2019; Gräßler et al., 2017). The foundations werederived from the procedural model of Reibnitz (Reibnitz, 1992). The Procedural Model for agile Strategic Planning is shown in figure 3.

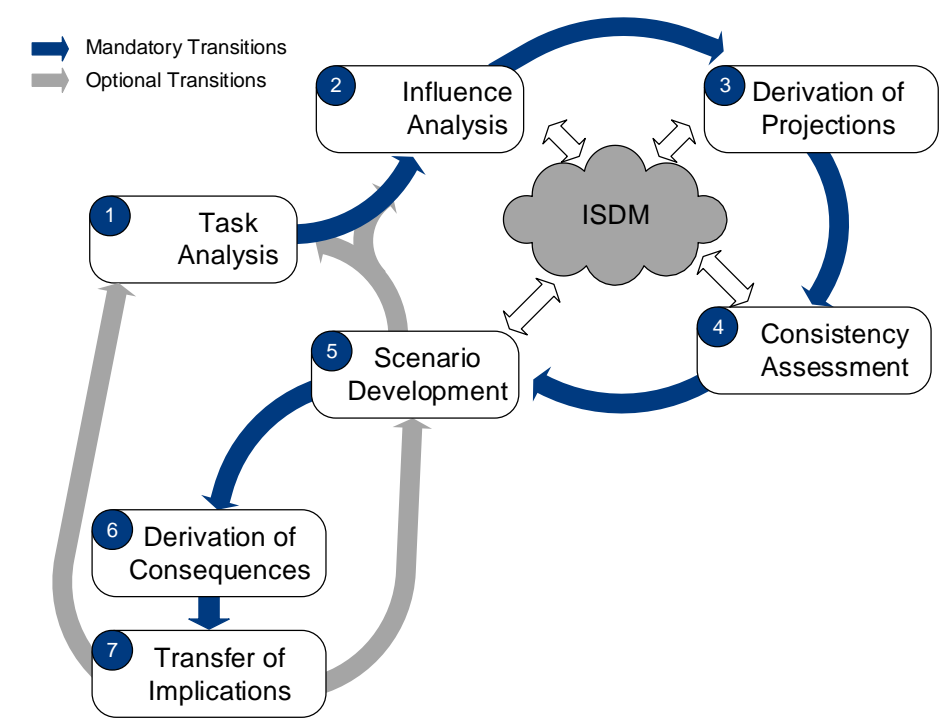

Figure 3: Procedural model for agile scenario-technique (Gräßler et al., 2017; Graessler et al., 2019) 
This paper was presented at The ISPIM Innovation Conference - Innovating in Times of Crisis, 7-10 June 2020.

Event Proceedings: LUT Scientific and Expertise Publications: ISBN 978-952-335-466-1

By applying the seven process steps, users are enabled to efficiently generate market scenario for various applications. As a method of foresight, the scenarios are the most consistent future rather than the most probable as in methods of forecast (Fink et al., 2000). The procedural model for agile scenario-technique is combined with the Integrated Scenario Data Model (ISDM) proposed by Graessler and Pottebaum (Pottebaum and Gräßler, 2016). Within the ISDM, all relevant data such as influence factors, their projections and underlying statistics as well as generic tasks and selection rules for certain process steps within the procedural model are stored. By combining both, the procedural and the data model, the agility of the scenario process can be enhanced, the communicative function of scenarios can be increased and the required effort for scenario generation can be reduced significantly (Graessler et al., 2020).

The input is particularly generated by references to the ANYWHERE Common Information Space. For the application in the ANYWHERE project, a generic catalogue of influence factors and other data was elaborated. The ANYWHERE-tailored ISDM contains 59 influence factors describing various aspects influencing future markets for innovative self-preparedness and self-protection tools (Gräßler et al., 2018). Aspects included were societal, market, technological and economic influence factors as well as aspects of PPDR (Gräßler et al., 2018). An exemplary influence factor is shown in table 1.

Table 1: Description and projections for the influence factor B1 "Potential threat by extreme weather events" (Gräßler et al., 2018)

\begin{tabular}{|c|c|c|c|c|c|c|}
\hline $\begin{array}{l}\text { Influence } \\
\text { field }\end{array}$ & \# & Name & Source & Description & $\begin{array}{l}\text { Projection } \\
\text { ID }\end{array}$ & Description of projection \\
\hline \multirow{3}{*}{$\begin{array}{l}\frac{2}{0} \\
\frac{0}{0} \\
0 \\
\mathscr{n}\end{array}$} & \multirow{3}{*}{1} & \multirow{3}{*}{$\begin{array}{l}\text { Potential } \\
\text { threat by } \\
\text { extreme } \\
\text { weather } \\
\text { events }\end{array}$} & \multirow{3}{*}{$\begin{array}{l}\text { Data base } \\
\text { (Munich } \\
\text { RE) }\end{array}$} & \multirow{3}{*}{$\begin{array}{c}\text { This influence } \\
\text { factor describes } \\
\text { the real } \\
\text { (measureable) } \\
\text { global threat by } \\
\text { extreme weather } \\
\text { events. }\end{array}$} & $1 \mathrm{~A}$ & $\begin{array}{l}\text { The number of extreme weather events } \\
\text { increases up to } 825 \text { per annum globally. }\end{array}$ \\
\hline & & & & & 1B & $\begin{array}{l}\text { The number of extreme weather events } \\
\text { remains constant at a number of } 750 \\
\text { events per annum globally. }\end{array}$ \\
\hline & & & & & $1 \mathrm{C}$ & $\begin{array}{c}\text { The number of extreme weather events } \\
\text { decreases to } 675 \text { events per annum } \\
\text { globally. }\end{array}$ \\
\hline
\end{tabular}

The procedural model for agile strategic planning and the ANYWHERE-tailored ISDM were made available to enterprises with potential services and tools for innovative selfpreparedness and self-protection. Both - procedural and data model - were implemented into a software tool based on Mathworks Matlab. The tool can on the one hand be applied by users already using forecasting tools to adopt self-preparedness strategies and can on the other hand be used by third parties to generate innovations for the self-preparedness market incorporating ANYWHERE services.

The tool was applied and validated within the four case studies of the project: schools, food logistics, camp sites and electricity providers. All user implemented forecasting tools of the ANYWHERE platform to predict direct impacts on their respective systems most probable in a foreseeable future. The additional implementation and application of the foresight tool yielded different strategies for each applicant. A reduced effort for strategic planning and an increased awareness of potential future developments of the relevant markets and the underlying influence factors was shown by the application.

The added value of the implementation of both methods of forecasting and foresight can be shown by using the data of a mechatronic system as input for forecasting methods and subsequently for the scenario tool. The water level, resulting from a low cost water 
level warning system, was used as an input for the prediction of the water level (Gräßler $e t$ $a l ., 2019)$. As the water level is one influence factor of the scenarios of the user, changes in strategies for the user are suggested in correspondence with passing of a specified threshold. The application of the scenario tool helped to take measures relevant to the user otherwise not taken as the underlying disruptive events are low in probability.

Despite the four case studies, the procedural model for agile strategic planning and the ANYWHERE-tailored ISDM were applied for the anticipation of market scenarios for another, additional case study: the autonomous city car. In collaboration with a German automotive supplier, product ideas using the ANYWHERE services were identified. The identified product ideas are based on existing products developed for OEMs or distributed independently, as well as new ideas. To identify the product ideas, the generic influence factors of the ANYWHERE-SDM were expanded by factors, relevant to the automotive supplier. An excerpt is shown in Table 2.

Table 2: Application Case "Autonomous Car": consolidated influence factors

\begin{tabular}{|c|c|c|c|c|}
\hline Influence field & \# & Name & Source & Description \\
\hline society & 15 & $\begin{array}{l}\text { Interest in } \\
\text { autonomous } \\
\text { driving }\end{array}$ & statista & $\begin{array}{l}\text { Share of consumers who are } \\
\text { interested in at least one add-on } \\
\text { service for an autonomous ride in } \\
\text { Europe }\end{array}$ \\
\hline economy & 17 & $\begin{array}{l}\text { sales of } \\
\text { automobiles }\end{array}$ & $\begin{array}{l}\text { VDA; } \\
\text { KBA }\end{array}$ & $\begin{array}{l}\text { Number of passenger cars sold in } \\
\text { Germany from } 2004 \text { to } 2019\end{array}$ \\
\hline
\end{tabular}

Based on the generic and specific influence factors scenarios for innovations in the market of self-preparedness for the automotive supplier were identified. In the ANYWHERE project, based on the works of Gassmann (Gassmann, 2013), Business Models suitable for the self-preparedness market were identified. By examining the Business Models in accordance to the identified scenarios 7 potential products were identified and elaborated.

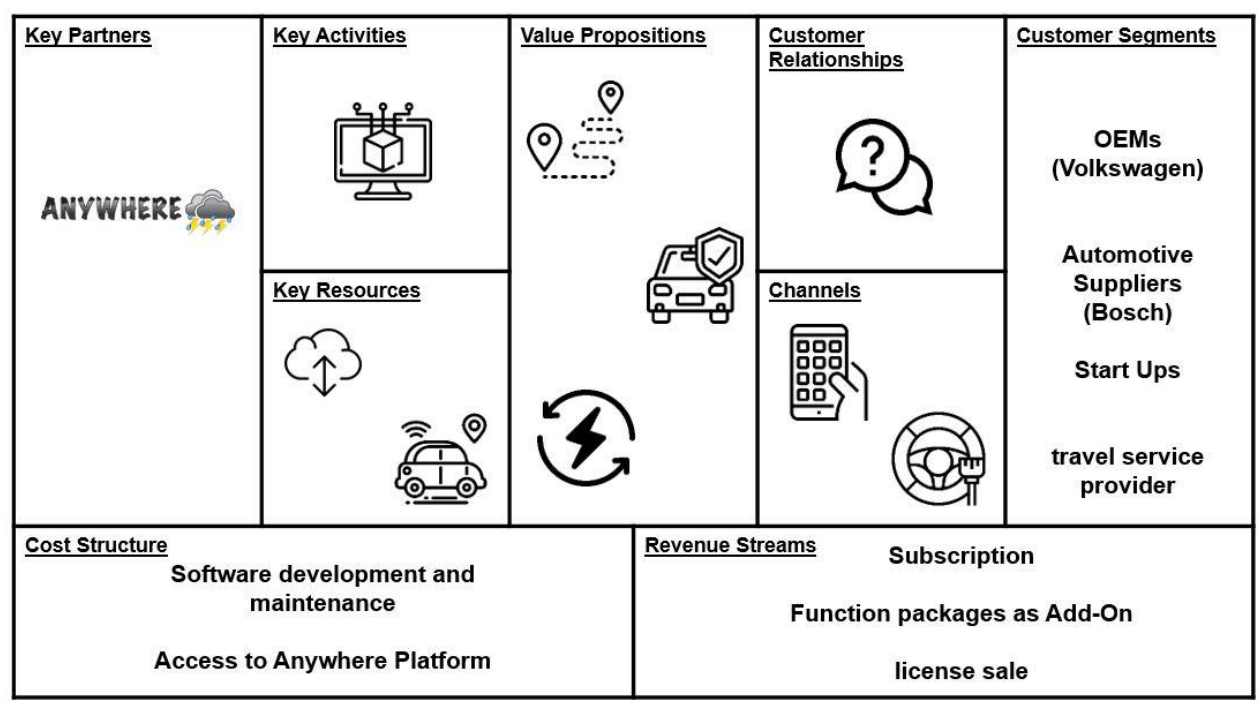

Figure 4: Business Model Canvas for the smart navigation software add-on 
As the automotive supplier plans to expands its product portfolio the field of autonomous driving, an add-on service to conventional navigation software was chosen to be pursued. Based on the ANYWHERE services, e.g. air pollution or rain forecasting, smart routes are calculated. The resulting Business Model Canvas is shown in Figure 4. This case study proved the possibility of generating innovations for the self-preparedness market, based on ANYWHERE services.

\section{Conclusions}

The approach contributes knowledge regarding innovation in markets involving public and economic stakes. Though the market potential is large, compliance with regulations seems complex and willingness to pay is challenging. Identification of markets and potential services for such boundary conditions was outlined by the work in the ANYWHERE project. Targeting both new innovative services as well as add-ons for established service frameworks was identified as key success factor of innovation in the difficult market of self-preparedness and self-protection services for citizens and enterprises. The new ANYWHERE approach towards strategic planning and corporate foresight combines fundamental domain knowledge, out-of-the-box thinking and agile scenario technique.

\section{Acknowledgements}

The H2020 ANYWHERE project is supported by the European Commission (Grant Agreement No. 700099). We would like to thank all ANYWHERE partners. Special thanks are dedicated to the leaders of case study teams: Xavier Llort (HYDS S.L., Barcelona), Ilona Láng (Finnish Meteorological Institute, Helsinki), Ivan Tesfai (RINA, Milano), Marc Berenguer (CRAHI UPC, Barcelona) and Nicola Rebora (CIMA Foundation, Genoa).

\section{References}

Fink, A., Schlake, O. and Siebe, A. (2000), "Wie Sie mit Szenarien die Zukunft vorausdenken. Was Szenarien für die Früherkennung leisten und wie sie konkrete Entscheidungen unterstützen”, Harvard Business Manager Special Issue.

Gassmann, O. (2013), Geschäftsmodelle entwickeln: 55 innovative Konzepte mit dem St. Galler Business Model Generator, Hanser, München.

Graessler, I., Scholle, P. and Thiele, H. (2019), "Scenario-Technique", in Vajna, S. (Ed.), Integrated Design Engineering: Interdisciplinary and holistic product, Springer International Publishing, Basel.

Graessler, I., Scholle, P. and Thiele, H. (2020), "Improving scenario-technique by a semiautomatized consistency assessment based on pattern recognition by artificial neural networks", paper presented at DESIGN, Dubrovnik.

Gräßler, I., Pottebaum, J. and Scholle, P. (2017), "Integrated Process and Data Model for Agile Strategic Planning", paper presented at IDE Workshop, 05.04. - 07.04., Magdeburg.

Gräßler, I., Pottebaum, J. and Scholle, P. (2018), "Influence Factors for Innovation in Digital Self-Preparedness Services and Tools", International Journal of Information Systems for Crisis Response and Management, Vol. 10 No. 1, pp. 20-37. 
Gräßler, I., Scholle, P. and Thiele, H. (2019), "Strategische Planung in Plattformen und Eco-Systemen mittels Szenario-Technik”, 27.-28.03.2019, Paderborn.

Gruchmann, Y., Schmidt-Bordemann, D., Skrzypietz, T. and Stuchtey, T.H. (2014), Die Sicherheitswirtschaft in Deutschland 2013: Marktanalyse einer dynamischen Wachstumsbranche, BIGS Studie, Brandenburg, available at: https://www.bigspotsdam.org/images/Studien/Studie\%20WISIND\%202.\%20Ergebnisbericht\%20Druc kversion.pdf (accessed 14 May 2020).

Paton, D. and Johnston, D. (2001), "Disasters and communities: vulnerability, resilience and preparedness", Disaster Prevention and Management: An International Journal, Vol. 10 No. 4, pp. 270-277.

Pottebaum, J. and Gräßler, I. (2016), "Reliable Input for Strategic Planning: The Integrated Scenario Data Model”, paper presented at 6th International Conference Production Engineering and Management, 29.-30.09.2016, Lemgo, Germany.

Reibnitz, U.v. (1992), Szenario-Technik: Instrumente für die unternehmerische und persönliche Erfolgsplanung, 2nd ed., Gabler, Wiesbaden.

Terti, G., Ruin, I., Kalas, M., Láng, I., Cangròs i Alonso, A., Sabbatini, T. and Lorini, V. (2019), "ANYCaRE: a role-playing game to investigate crisis decision-making and communication challenges in weather-related hazards", Natural Hazards and Earth System Sciences, Vol. 19 No. 3, pp. 507-533.

van Lanen, H.A.J., Vitolo, C., Di Napoli, C., Sutanto, S., D’Andrea, M., Bergman, T., Duo, E., Montblanc, T.F., Gascón, E., Di Giuseppe, F. and others (2019), “A panEuropean multi-hazard early warning system: ANYWHERE MH-EWS”, Geophysical Research Abstracts 2019, Vol. 21.

Venier, S. and Capone, F. (2019), "Speaking with One or Multiple Voices in MultiHazard Early Warning Systems? A Survey of International and National Legal and Policy Frameworks", in Samuel, K., Aronsson-Storrier, M. and Bookmiller, K.N. (Eds.), The Cambridge handbook of disaster risk reduction and international law, Cambridge University Press, Cambridge, pp. 150-169. 